\title{
QUEM VOCÊS PENSAM QUE (ELAS) SÃO? - REPRESENTAÇÕES SOBRE AS PESSOAS EM SITUAÇÃO DE RUA*.
}

\author{
Ricardo Mendes Mattos \\ Ricardo Franklin Ferreira \\ Universidade São Marcos
}

RESUMO: No ponto de encontro entre o conceito de identidade como metamorfose humana e a categoria ideologia como forma de reproduzir relações sociais de dominação, o presente artigo discute a tipificação das pessoas em situação de rua como vagabundas, sujas, loucas, perigosas e coitadas. Tal conhecimento socialmente compartilhado acaba por legitimar a violência física contra estas pessoas, bem como servir de referência para a constituição de suas identidades pessoais. Face a este universo simbólico perverso que as acomete, são analisados a loucura (como fuga da realidade), o suicídio (como consumação material da morte simbólica em curso) e a resistência, a partir da transformação social (opondo-se a esta ideologia através da luta pelos seus direitos), como formas das pessoas em situação de rua elaborarem estas representações oriundas de suas condições sociais.

PALAVRAS-CHAVE: psicologia social; situação de rua; identidade; ideologia; representação social.

WHO DO YOU THINK THEY ARE? - REPRESENTATIONS ABOUT HOMELESS PEOPLE.

ABSTRACT: In the rendezvous of the concept of identity as cause of the human metamorphose and the category of ideology as a way to reproduce social domination, the present article discusses the labeling of the homeless people as vagabonds, dirty people, crazy persons, dangerous or poor. This feeling shared for many ends up to legitimate the physical violence against this people, as well as a bad reference in the constitution of their personal identities. Besides this perverse symbolic universe which they're submitted, are analyzed the madness- as escape from reality, the suicide - as the material consummation of the symbolic death, and the resistance against the social transformation- as an opponent to this labeling through the fight for their rights.

KEY-WORDS: social psychology; homelessness; identity; ideology; social representations.

\section{INTRODUÇÃO}

Quantos dentre nós, em meio às atividades corriqueiras, nos deparamos com a figura de um morador de rua? Considerando que eles habitam com freqüência vários logradouros públicos, é pertinente ponderar que todos nós já interagimos com essas pessoas.

Contudo, se refletirmos sobre a qualidade destas interações, observaremos que comumente nós as olhamos amedrontados, de soslaio, com uma expressão de constrangimento. Alguns as vêem como perigosas, apressam o passo. Outros logo as consideram vagabundas e que ali estão por não quererem trabalhar, olhando-as com hostilidade. Muitos atravessam a rua com receio de serem abordados por pedido de esmola, ou mesmo por préconceberem que são pessoas sujas e mal cheirosas. Há também aqueles que delas sentem pena e olham-nas com comoção ou piedade. Enfim, é comum negligenciarmos involuntariamente o contato com elas. Habituados com suas presenças, parece que estamos dessensibilizados em relação à sua condição (sub) humana. Em atitude mais violenta, alguns chegam a xingá-las e até mesmo agredilas ou queimá-las, como em alguns lamentáveis casos noticiados pela imprensa.

Observa-se, assim, a existência de representações sociais pejorativas, em relação à população em situação de rua, que se materializam nas relações sociais. Vagabundo, preguiçoso, bêbado, sujo, perigoso, coitado, mendigo... São designações comuns dirigidas às pessoas em situação de rua.

Estes conteúdos interferem na constituição da identidade destas pessoas: é conhecimento socialmente compartilhado e utilizado como suporte para a construção de suas identidades pessoais. 
Mattos, R.M.; Ferreira, R.F. "Quem vocês pensam que (elas) são? Representações sobre as pessoas em situação de rua"

Trata-se de conteúdos simbólicos de cunho ideológico, na medida em que favorecem a cristalização de relações de exploração e dominação (GUARESCHI, 1996, 2002).

Guareschi (1996) faz alusão a algumas "estratégias de operação da ideologia", dentre elas a "rotulação ou estigmatização" (p. 90). Uma das formas possíveis de se entender este mecanismo é a partir do conceito de "esquemas tipificadores" (BERGER e LUCKMANN, 1985). Estes constituem um conhecimento socialmente compartilhado do qual lançamos mão para apreender o outro nas interações sociais. Segundo os autores, estes esquemas pressupõem uma "anonimidade inicial", na medida em que se trata de um pré-conceito para apreender o outro, que precede e "modela" a interação com ele. Ao serem transmitidos para as gerações seguintes, estes conteúdos, como qualquer institucionalização, acabam por ser revestidos de um caráter a-histórico, surgindo como construções simbólicas "dadas, inalteráveis e evidentes” (BERGER e LUCKMANN, 1985, p. 85). O ápice da "tipificação" é a completa apreensão da pessoa como um "tipo", somente pelos aspectos rotulados, negando sua humanidade e a transformação a ela inerente. A identidade como metamorfose (CIAMPA, 1990), entendida como uma construção ininterrupta a partir das relações sociais em um contexto histórico determinado, surge assim sob a aparência de uma "identidade reificada" (BERGER e LUCKMANN, 1985, p. 126), manipulada pelas tipificações externas à pessoa e que, por sua vez, atrofiam sua possibilidade de autonomia.

A relação da ideologia com a identidade (CIAMPA, 1977) ou das representações sociais com a subjetividade (FURTADO e GONZALEZ REY, 2002) não são investigações simples, nem tampouco recentes. Sabe-se que a construção da identidade está vinculada à totalidade das relações sociais, recortada pelo conhecimento socialmente compartilhado e mediado por outrem (CIAMPA, 1990; BERGER e LUCKMANN, 1985). Assim, qualquer estudo sobre a identidade de uma pessoa deve ser precedido do conhecimento das representações sociais sobre a categoria na qual está inserida.

Compreendemos 'representação social', neste trabalho, como a categoria definida por Jodelet (2001), ou seja

uma forma de conhecimento, socialmente elaborada e partilhada com um objetivo prático, e que contribui para a construção de uma realidade comum a um conjunto social. Igualmente designada como saber de senso co- mum ou ainda saber ingênuo, natural, esta forma de conhecimento é diferenciada, entre outras, do conhecimento científico (p. 22)

As representações sociais organizam as condutas e as comunicações sociais e intervêm na difusão e na assimilação dos conhecimentos, além de participar na definição das identidades pessoais e sociais.

Para Moscovici (1978), são referências que "circulam, cruzam-se e se cristalizam incessantemente através de uma fala, um gesto, um encontro, em nosso universo cotidiano" (p. 41). Além disso, para Moscovici (2003), elas convencionalizam os objetos e pessoas e, além de darem a eles uma forma definitiva, transformamnos em modelos de determinado tipo que passam a ser partilhados pelas pessoas na construção de suas 'realidades'.

Neste trabalho, as representações sociais como "modelos" compartilhados pelas pessoas em suas relações cotidianas, conforme a concepção de Moscovici (2003), assemelha-se ao que entendemos como "esquemas tipificadores", propostos por Berger e Luckmann (1985).

Assim, a proposição aqui discutida é clara: as representacõos sociais sobre as pessoas em situação de rua reforçam a construção de identidades articuladas com valores negativamente afirmados. Neste caso específico, as representações sociais podem ser consideradas ideológicas, pois re-produzem e cristalizam relações concretas de dominação (OLIVEIRA e WERBA, 2002). Em contrapartida, consideramos que as mesmas representações contêm em si o germe de sua superação, podendo servir como referências para o ingresso das pessoas em situação de rua no campo da reivindicação pelos seus direitos, constituindo, por conseguinte, identidades mais críticas e autônomas.

A partir desse contexto, o objetivo deste artigo é traçar um breve esboço sobre como as representações sociais acerca de pessoas em situação de rua repercutem na construção de suas identidades.

Para tanto, foram referenciados alguns depoimentos de ex-moradores de rua que tiveram suas histórias de vida analisadas por Mattos (2003), em sua pesquisa sobre a identidade das pessoas em situação de rua. Utilizamos também nossa experiência e participação em alguns movimentos sociais articulados pela população em situação de rua, além de duas publicações sobre este contingente: o Jornal "O Trecheiro: notícias do povo da rua" (em suas edições $n^{\circ}$ 98, 105 e 108) e a "Revista 
Boca de Rua" (especificamente os $n^{\circ}$ s 0, 1, 2 e 3). A publicação mensal do jornal "O Trecheiro: notícias do povo da rua" constitui um excelente meio de comunicação realizado com e para a população em situação de rua da cidade de São Paulo. "O Trecheiro" é editado pela Rederua (www.rederua.org.br) com o intuito de dar "vez e voz" ao povo da rua, sendo um instrumento de comunicação dos acontecimentos vivenciados nas ruas paulistanas. Possui uma linha editoria calcada na denúncia e discussão de estratégias para a assistência à população em situação de rua. Destacamos, em nossa análise, os relatos de diversas pessoas em situação de rua que compõem o espaço denominado "Vida no trecho".

A "Revista Boca de Rua" possui toda sua linha editorial, matérias e reportagens realizadas pelas próprias pessoas em situação de rua de Porto Alegre. Este projeto segue a mesma linha de iniciativas similares organizadas pela INSP, uma Rede Internacional de Jornais de Rua, abarcando, além de instrumento de conhecimento e divulgação dos acontecimentos da rua, a venda da revista como uma fonte de renda para este contingente. Concentramos nossa análise em algumas passagens do jornal que deflagram a postura crítica de seus realizadores sobre a vida nas ruas. Assim, a partir dos depoimentos de pessoas em situação de rua, a presente exposição discute algumas tipificações comumente infligidas às pessoas em situação de rua e aponta alguns de seus efeitos na constituição de suas identidades.

\section{PESSOA EM SITUACC̃O DE RUA COMO VAGABUNDA}

O trabalho (entendido em seu sentido produtivo de venda de força de trabalho e extração da mais-valia) constitui uma das categorias responsáveis pela coesão da sociedade atua (ENRIQUEZ, 1999; TOSTA, 2000), além de conferir ao indivíduo dignidade pessoal (VIEIRA, BEZERRA e ROSA, 1992). Dessa forma, o trabalho surge como fator primordial para a pessoa, por dois aspectos: provém a subsistência física por meio dos rendimentos auferidos; e sustenta a subsistência simbólica, dada a importância do trabalho (ou identidade profissional) na constituição da identidade pessoal (JACQUES, s.d.; BAPTISTA, 2002). Releva-se ainda o fato de que o emprego formal e o registro em carteira servem como legitimadores da identidade de trabalhador (embora quase a metade dos trabalhadores atue no mercado informal). Desprovidas desta referência, as pessoas em situação de rua, apesar de desenvolverem atividades nformais, são, sob a ótica do trabalho, freqüentemente consideradas como improdutivas, inúteis, preguiçosas e vagabundas.

Segundo Di Flora (1987), a população em situação de rua é assim estigmatizada, pois escancara as contradições básicas do modo capitalista de produção: a falácia de que todos possuem iguais oportunidades e a evidência de que, embora a produção seja social, a apropriação dos ganhos é sempre individual, sendo as pessoas em situação de rua testemunhas vivas de que a exploração e a desigualdade estão no cerne deste modo de produção.

Neste sentido, estas contradições são solapadas a partir de um mecanismo denominado "culpabilização" (GUARESCHI, 1999). Este mecanismo é considerado como uma legitimação ideológica que suporta a criação e reprodução das relações de exploração e dominação no capitalismo. Frente à (pseudo) igualdade e à competitividade inerente ao ideal liberal, qualquer problemática que envolva a inserção do indivíduo no sistema produtivo é alvo de um reducionismo que o descontextualiza da sociedade e transfere-lhe a culpa e responsabilidade por sua condição. Para Di Flora (1987), esta "culpabilização" advém de um radical "psicologismo", quando as causas são consideradas como individuais. Em função disso, a pessoa sem emprego formal é rotulada como "anormal ou desviante", ou seja, a culpa da ausência de trabalho recai sobre a própria vítima. Assim, ocorre a "tipificação" do indivíduo em situação de rua como vagabundo, incapaz e "sujeito que não quer trabalhar" (DOMINGUES JR. 1998 , p. 14), pela sociedade no geral e até por outras pessoas em situação de rua. Aos cidadãos que reproduzem estes estereótipos, o depoimento de José pode ajudá-los a repensar nos valores que possuem acerca da população em situação de rua: "O pessoal que está aqui não é por falta de capacidade. Não é nossa culpa. Eles acham que não temos aparência, mas não temos como nos cuidar" (TRECHEIRO, Ano X, no 98, p. 03).

\section{PESSOA EM SITUAÇÃO DE RUA COMO LOUCA}

Como se não bastasse a corriqueira denominação das pessoas em situação de rua como vagabundas, há também o "discurso psiquiátrico", segundo denominação de Stoffels (1977), que as identificas como "doentes mentais", "loucas" e "desviantes sociais". Este conteúdo, difundido no senso comum, assume que a mendicância pode ser considerada, de modo geral, "como gênese e produto de distúrbios de personalidade, doenças men- 
Mattos, R.M.; Ferreira, R.F. "Quem vocês pensam que (elas) são? Representações sobre as pessoas em situação de rua"

tais ou psicopatia..." (p. 262)

Permeado pelo critério psiquiátrico de patologia como sinônimo de anormalidade, em contraposição aos indivíduos considerados "normais", muitas vezes as pessoas em situação de rua são vistas como "loucas" ou "casos de internação". A caracterização das pessoas em situação de rua como anormais, carrega em si a comparação com uma "normalidade" vista como forma legítima de vida na sociedade. Assim, o diferente passa a ser objeto de estranhamento e repulsa. A dicotomia "normal" versus "anormal" homogeneíza as diferenças com o intuito de "manter todos na linha", re-produzir uma dada ordem social. Ora, se morar em uma residência fixa, trabalhar formalmente e constituir família são padrões sociais que caracterizam os indivíduos "normais", logo, sem residência fixa, sem família e trabalho formal, as pessoas em situação de rua são alvos de investidas ideológicas que acentuam suas "anormalidades".

Assim é que o "discurso psiquiátrico" associa a população de rua à doença mental caracterizando-a pelos "desajustamentos sociais", "psicopatias" e "distúrbios de personalidade" (STOFFELS, 1977, p. 262).

\section{PESSOA EM SITUAÇÃO DE RUA COMO SUJA}

Magni (1994) oferece respaldo para a discussão sobre a tipificação das pessoas em situação de rua associadas à sujeira e ao contágio de doenças - fato que subverte e afronta nossos hábitos de higiene e preservação da saúde. Segundo a autora, a clássica descrição dessas pessoas como "arquétipo do fedor" é um exemplo claro desta estigmatização:

O estereótipo do nômade urbano é clássico: roupa esfarrapada, pele encardida com dermatoses, às vezes abrindo em feridas, corpo marcado por cicatrizes; unhas das mãos e dos pés enegrecidas, compridas e, por vezes, deformadas; dentes em parte caídos, em parte cariados; cabelos ensebados, olhos congestionados, etc. São signos genéricos que contam a trajetória social e tornam evidente que o indivíduo faz parte da população pobre que habita as ruas (p. 134).

Sempre que nos referimos a essas pessoas, é comum automaticamente ocorrer a associação com a difundida figura de um indivíduo sujo, maltrapilho e aparência sórdida. Nesse caso, estamos utilizando o "discurso higienista" que rotula e propaga o estigma do morador de rua sempre associa- do à sujeira que deve ser jogada para "debaixo do tapete". Entretanto, o que nos deixa perplexos, e deve ser ressaltado, é que a grande maioria dos indivíduos que habitam as ruas não compartilha destes atributos.

Nesse sentido, Sposati (1995) ressalta a constante demanda dos cidadãos em solicitar a "remoção" de moradores de rua que estão localizados perto de suas residências. Assim, realiza-se um trabalho baseado no "modelo filantrópico higiênico" ou "concepção asséptica" na qual "a orientação do trabalho é segregar, esconder, higienizar" (p. 90). O lema é: "vamos recolher as pessoas, vamos dar banho, vamos tirar a sujeira" (p. 89).

\section{PESSOA EM SITUAÇ̃̃OO DE RUA}

COMO PERIGOSA

Ao analisar os "discursos ideológicos" que rotulam as pessoas em situação de rua, Stoffels (1977) aponta o "discurso jurídico" e "criminológico" que as apreende como "perigosas" e "criminosas", sucessivamente (p. 38)

Nesse sentido, vejamos o depoimento de Jorge, um ex-morador de rua (MATTOS, 2003):

Elas tinham medo de chegar e se aproximar. Eu acho que esse é o maior erro do povo brasileiro... ter esse medo. Então eu acho que deveriam de ser cortadas essas barreira... Elas ficam com medo, como se a pessoa... você dar um choque se ela fosse falar com ela. Porque ninguém mata, eu posso conversar com determinada pessoa sem pegar uma doença e nem nada... (p. 42).

Relata o medo das pessoas que passavam na praça de conhecer e conversar com as pessoas em situação de rua. Este medo talvez esteja relacionado ao estigma do morador de rua como um criminoso em potencial, que pode assaltar, pedir esmola ou violentar quem quer que atravesse o seu caminho. As pessoas, ainda segundo Jorge, pensam que vão levar um 'choque' aproximando-se dos cidadãos em situação de rua. De fato, levarão um 'choque': o 'choque' da desigualdade e desumanização do homem no seio da sociedade brasileira.

Trata-se da vinculação mais geral da pobreza com a violência e a delinqüência, o que vem a favorecer que todos os cidadãos enxerguem o morador de rua como 'socialmente ameaçador' e um 'criminoso em potencial'. 


\section{PESSOA EM SITUAÇÃO DE RUA COMO "COITADINHA"}

Por fim, apesar de não dispormos de dados na literatura, a partir de contatos que se deram com pessoas em situação de rua, durante o levantamento de dados da pesquisa de Mattos (2003), identificamos um outro tipo de discurso que permeia as relações entre essas pessoas e os domiciliados - um discurso que denominamos de "discurso religioso", que contém uma visão sobre as pessoas em situação de rua como aquelas dignas de piedade.

É uma concepção que procura explicar a situação de rua como uma oportunidade de expiação de erros cometidos em vidas passadas, ou seja, como um modo de vida de sofrimento que pode levar à salvação pessoal. Assim, a situação de rua passa a ser vista como uma condição de "regeneração da alma". Mesmo existindo uma sincera piedade, o aspecto pernicioso que atua subjacente a esta concepção é o de contribuir para a construção da identidade do indivíduo em situação de rua como alguém inferior e digno de pena por suas mazelas, além de ser uma crença que dificulta a criação de possibilidades para estes indivíduos conquistarem suas saídas das ruas. É uma visão que favorece ações meramente assistencialistas e paliativas, o que, provavelmente, tende a manter o problema.

\section{DA TIPIFICAÇÃO À VIOLÊNCIA FÍSICA}

O conjunto destas tipificações suscita nos cidadãos domiciliados ações que trafegam no extremo da total indiferença chegando até à repulsa e à violência física.

O contato corriqueiro com pessoas em situação de rua, que no início gerava espanto e indignação, vai gradualmente levando a uma dessensibilização para com sua condição social. De tão acostumados com suas mazelas, mesmo que involuntariamente, já não mais reparamos suas presenças. Trata-se da disseminação da indiferença que denota uma "naturalização" do fenômeno pelos indivíduos sedentários: "as coisas são mesmo assim. O que posso fazer?" - exclamam. Assim, reproduzem uma visão que propaga a situação de rua como definitiva, imutável, defronte à qual os sujeitos históricos, que constroem a realidade social, nada podem fazer.

Nascimento (2000) relata que, subjacente à indiferença, pode estar atuando a desconsideração do outro da rua como igual, como se fosse de outra espécie com poucas similarida-
Psicologia \& Sociedade; 16 (2): 47-58; maio/ago.2004 des. São pessoas, portanto, negadas em sua humanidade: "homens e mulheres que não são mais vistos como tais por seus semelhantes. E talvez já não se sintam também como tais" (p. 56).

Cléver, outro ex-morador de rua (MATTOS,

2003), nos dá o seguinte depoimento:

...a rua é uma das fases mais cruéis que podem existir no ser humano. Eu acho que depois da guerra eu acho que a crueldade maior é ser um morador de rua. É uma guerra contra o silêncio, contra o descaso, contra uma coisa que muitos passam e nem olham, nem tomam conhecimento de quem está deitado ali, quem não está (p. 75).

No outro extremo, há uma atitude hostil de repulsa, nomeadamente a violência física, como atitude legitimada pela existência destas tipificações. Esta é a idéia discutida por Bursztyn (2000), quando pondera que a "desqualificação" e a "desvinculação" das pessoas em situação de rua pode ser seguida da "eliminação" física à qual elas estão suscetíveis. Buarque (2000) acrescenta que pode estar em andamento um processo de "dessemelhança entre seres humanos", marcado pela imagem do cidadão em situação de rua como alguém destituído do pertencimento à espécie humana.

Cléver, participante da pesquisa de Mattos (2003), na época que habitava o baixio de um viaduto próximo à favela de Heliópolis, em São Paulo, relata que não dormia, em parte pelo medo de que "vândalos" tentassem queimá-lo.

Noticiários constantes também corroboram a existência de muitos casos de homicídios de pessoas em situação de rua. Além do conhecido caso do assassinato do índio Galdino em Brasília, é muito freqüente a ocorrência de lamentáveis fatos como este, embora não tenham a mesma repercussão.

Eis a tese de que a violência simbólica, que por si só já acarreta danos intransponíveis através das atitudes e das palavras, legitima a ocorrência de violência física, que pode chegar ao extremo da eliminação física.

INTERIORIZAÇÃO DOS DISCURSOS: "SOU UMA PESSOA VAGABUNDA, LOUCA, SUJA, PERIGOSA E DIGNA DE PIEDADE?"

Somente a existência destes atributos jâ pontua a ocorrência de uma violência simbólica para com a população em situação de rua que, como vimos, legitima a ocorrência da violência física. Contudo, a faceta mais contundente é o fato 
Mattos, R.M.; Ferreira, R.F. "Quem vocês pensam que (elas) são? Representações sobre as pessoas em situação de rua"

dessas pessoas utilizarem estes conteúdos como referência para configurarem suas próprias identidades.

Sob o prisma de Ciampa (1990), configuramos nossa identidade a partir da interiorização de atributos pressupostos pelos outros em nossas interações, tendo como pano de fundo o conhecimento socialmente compartilhado. A existência de "esquemas tipificadores" possui a condição de predizer e manipular as condutas individuais na medida em que "define e constrói os papéis" e, por conseguinte, "controla e prediz todas essas condutas" (BERGER e LUCKMANN, 1985, p. 93). Com base nestes papéis objetivamente atribuídos, o indivíduo constrói personagens subjetivamente apropriados.

Assim, os conteúdos simbólicos emergentes nas relações sociais construídas pelo indivíduo com seus interlocutores tornam-se referências que passam a ser apropriadas intrapsiquicamente. Isto não quer dizer que o indivíduo aceite de bom grado tais tipificações, mas que as têm como conteúdos subjetivos em torno dos quais ele dá sentido às suas vivências e constrói sua identidade pessoal, mesmo que sejam por ele negados (MATTOS, CASTANHO e FERREIRA, 2003).

Diversos estudos e os próprios depoimentos de pessoas em situação de rua apontam que há uma apropriação das representações sociais a elas atribuídas e, através delas, dão sentido às suas identidades e às condições sociais a que estão submetidas.

Nesse sentido, Cléver nos dá seu depoimen-

O morador de rua não é só aquele que está debaixo do viaduto, dormindo debaixo de uma coberta, ou mesmo num asfalto ou numa calçada fria, mas é aquele morador que um dia ele teve uma cama quente, um dia ele teve um lar, ele teve uma cultura na vida dele. Mas como se fosse numa fração de segundos, como um vírus no computador, aquilo deu um "tilt" na vida dele. E ele parou de funcionar, e ele foi parar ali, como se fosse um depósito de ferro velho. Sem ter alguém, um mecânico que fosse lá tentar descobrir onde estava o problema, tentar descobrir se tinha conserto ou não aquela peça... E cada vez mais, quanto mais tempo a pessoa fica colocada nesse depósito de ferro velho, que é o mundo aí fora, as calçadas e as esquinas da vida, aquele defeito vai de agravando de tal forma que vai tomando conta de todas as peças, ela vai enferrujando todas as suas partes. Chega um determinado momento que esta peça não tem mais vontade própria, nem sequer ela lembra que teve um passado. Ela começa a viver na verdade aquele sub-mundo que ela está vivendo e esquece que existe outro mundo. Ela começa a ver as pessoas que vivem nesse outro mundo como se fossem "ETs", como se fossem pessoas superiores a ela ao máximo. Por mais capacidade que essa pessoa tenha, ela não consegue botar isso para frente, ela não consegue botar isso para uma mudança da própria vida dela (MATTOS, 2003, p. 75).

Configurando sua identidade, a partir destes valores, acaba vivendo o que denomina uma das mais cruéis fases que podem existir ao ser humano. Justamente uma etapa na qual a própria humanidade lhe é negada. O cidadão em situação de rua não é visto como um igual, como integrante da mesma espécie, apenas não é visto, como se fosse coisa. Como analisamos, o indivíduo pode apropria-se das representações sociais e passar a ver-se como um objeto, 'uma peça sem vontade própria'.

Além disso, a pessoa também pode se apropriar do conteúdo ideológico da culpabilização e acreditar que está nestas condições devido somente a imperfeições individuais, responsabilizandose integralmente (NASCIMENTO, 2000, p. 63). Surgem, então, justificativas, também parciais, segundo as quais a pessoa está em situação de rua porque não estudou, não soube abraçar oportunidades de emprego ou não tenha pensado no futuro.

Por conseguinte, a pessoa pode incorporar uma visão de si própria como digna de menos valia, como um fracasso, ou seja: "vão pouco a pouco adquirindo a identidade dos caídos, dos inúteis, dos fracassados" (ZALUAR, 1995, p. 55).

Segundo Stoffels (1977), na representação que as pessoas em situação de rua concebem para sua existência permeada pela pobreza, a dicotomia pobreza/riqueza é vista como uma "contingência da natureza humana" cuja naturalização extrapola a atividade humana e é tida como uma força extrínseca e estranha aos homens. Ocorre a tendência à culpabilização pessoal ou aos desígnios traçados por Deus, como demonstram os depoimentos de seus entrevistados: "A miséria existe por falta de capacidade e oportunidade"; "O pobre é pobre porque não usou a cabeça"; "Ricos e pobres? 
Isto daí existe desde o começo do mundo"; "Essa diferença não é culpa de ninguém. É assim" (p. 208); "Desconfio que Deus já fez o mundo assim" (p. 209).

Por fim, "o indivíduo não-trabalhador é encerrado pela ideologia dominante numa situação periférica, e estigmatizado como ser desviante, degenerado e residual. Ele se vê e sente como elemento segregado, portador de uma identidade atrofiada" (STOFFELS, 1977, p. 231).

Tal fato repercute em diversos aspectos de sua vida: sentimento de vergonha e humilhação que o faz se afastar do contato com familiares; tendência ao isolamento ou formação de grupos que lhe confiram uma identidade estável.

Se muitos se calam resignados, incorporando os atributos de fracassados, outros negam tal prerrogativa e constroem seus sucessos pessoais ao narrem suas biografias (ORTIZ, 2001; BARBOSA e PAULINO, 2003), permeadas por críticas aos preconceitos sociais e à falta de oportunidades.

Observa-se, então, também a possibilidade de desenvolvimento de uma postura crítica na investigação da realidade concreta das pessoas em situação de rua em edições por elas produzidas, tais como a Revista Boca de Rua, utilizada como instrumento de denúncia das problemáticas que margeiam a vida nas ruas de Porto Alegre - tais como a "invisibilidade" social e a violência polici al (ano I, $\mathrm{n}^{\circ}$ 0), a drogadição (ano I, $\mathrm{n}^{\circ} 1$ ), a dificuldade de conseguir vagas em albergues (ano I, $\mathrm{n}^{\circ}$ 2) e a omissão de tratamento à saúde da população de rua (ano I, no 3 ).

Entre as próprias pessoas em situação de rua, suas relações indicam também para uma re produção destes discursos ideológicos que configuram a violência simbólica. Domingues Junior (1998), que desenvolveu sua pesquisa com catadores de materiais recicláveis, os quais, em sua maioria, já estiveram ou estão em situação de rua, espanta-se com o fato de existir a proliferação dos valores dominantes até no âmbito das diversas categorias que compõem a população em situação de rua: "portanto, se de um lado os catadores recusam a imagem que lhes é imposta, de vagabundos, que não querem trabalhar, etc, por outro, os catadores se conformam, reproduzem essa imagem realizada pela ideologia dominante, e repassamna para a população de rua" (p. 110)

Entretanto, ao lado destes, muitos catadores encabeçam movimentos sociai protagonizados pela população em situação de rua, tornando os cooperados uma espécie de vanguarda nas lutas desta população por suas reivindica-
Psicologia \& Sociedade; 16 (2): 47-58; maio/ago.2004

ções históricas. Outras vezes, contrapondo-se à tipificação de vagabundas, muitas pessoas em situação de rua reagem trabalhando com afinco em alternativas de trabalho que valorizam o ser humano como centro de toda atividade econômica tal como as experiências de economia solidária analisadas por Hayashida (2003) -, ou mesmo participando como trabalhadores em luta por importantes modificações sociais como a reforma agrária, ao ingressarem no Movimento dos Trabalhadores Rurais Sem-Terra - como visto por Shimabukuro (2003) e Costa e Magalhães (2002). Di Flora (1987) analisa a interiorização da desumanização como um aspecto que faz com que o cidadão em situação de rua não se sinta mesmo completamente humano: "a pressão da estrutura social e econômica, ao determinar o ingresso do indivíduo nesta categoria, condiciona-o à formação de uma nova identidade: a de mendigo socialmente estigmatizado e entendida como deteriorada, o que leva a não se sentir completamente humano" (p. 49).

Com tudo o que foi dito, não é de se espantar o depoimento de Mário, um cidadão em situação de rua entrevistado por Nasser (1996):

É triste! As pessoas passam de ônibus

- pessoal de carro não olha muito - e

ficam olhando e pensam: rapaz novo, em fila de albergue, tomando sopa... é vagabundo! Eles analisam assim.

Pensam que amanhã a gente vai sair e vai roubar. Todo pessoal de albergue é injustiçado. Pensam que é ladrão, maconheiro, estuprador. A gente fica condenado. Quando a gente vê, tem sempre umas pessoas olhando. Por dentro, a gente fica magoado

(p. 24).

As duas histórias de vida analisadas por Mattos (2003) indicam a existência nítida da representação ideológica da pessoa em situação de rua como suja. Cléver, um de seus colaboradores de pesquisa narra a seguinte vivência: "Com um simples olhar que te davam, você já se sentia envergonhado pelo lixo que você era. Você se olhava e perguntava: 'será que eu estou fedendo?' Porque com aquele olhar você sentia que era um olhar repugnante, como você olha para um cachorro sarnento" (p. 92). Jorge, o outro ex-morador de rua entrevistado por Mattos (2003), revela uma outra faceta da "tipificação" a que o cidadão em situação de rua está sujeito. Segundo ele, as pessoas sabiam julgar, mas não conheciam estas pessoas, não se aproximavam e até ficavam indiferentes ao vê-las. Vemos a ocorrência da indiferença, 
Mattos, R.M.; Ferreira, R.F. "Quem vocês pensam que (elas) são? Representações sobre as pessoas em situação de rua"

da negligência, da "invisibilidade social" dos indivíduos em situação de rua. Simplesmente passam despercebidos.

Em contrapartida, ainda na fala de Cléver (MATTOS, 2003), pode-se perceber fervorosas críticas às pessoas que desrespeitam as atividades desenvolvidas por pessoas em situação de rua. Referimo-nos especialmente a uma passagem de sua narrativa em que, trabalhando como catador, discute com uma cidadã cabeleireira que não permitira a ele remexer em um lixo no qual afirmava haver "cocô de gato": " 'Senhora, a senhora ganha dessa profissão que a senhora está fazendo cortando o cabelo?' - e a cliente olhando para a minha cara, eu falei: 'então eu vou meter a mão nesse cocô de gato, porque é desse cocô de gato que eu tiro o meu sustento'. Eu abri o saco e peguei o que eu queria. Então por aí você vê a discriminação que sofre a pessoa" (MATTOS, 2003, p. 97). Em outra ocasião reafirma sua visão crítica em relação às tipificações sofridas pelas pessoas em situação de rua nos albergues da cidade, pois, segundo ele, muitas destas instituições funcionam como "depósito humano", criando uma dependência institucional e não oferecendo condições para estas pessoas criarem suas próprias autonomias:

"E nada mais nada menos que esse

homem que se acostumou a comer,

beber e dormir sempre na dependên-

cia dos outros. Porquê? Porque as en-

tidades, a prefeitura, e não sei quem,

proporcionaram isso daí para ele. Dei-

xou para ele usufruir disso, não se

importou em pegar esse homem e

reciclar ele. Fazer ele ganhar o pão

dele de cada dia" (p. 112).

Em outras ocasiões, vemos pessoas em situação de rua que comparecem a encontros universitários (MATTOS e TUCCI, 2003) para "mostrar suas caras" e "quem realmente são", conforme suas palavras. Assim, contribuem para a desmistificação das tipificações e para a formação de profissionais mais engajados em causas sociais.

Poderíamos citar vários outros exemplos, tais como a mobilização da população em situação de rua em seu Dia de Luta (JORNAL "O TRECHEIRO”, ANO XII, n. 108), realizado anualmente para reivindicar alguns direitos que são escamoteados em virtude destas tipificações.

Analisando a identidade como o próprio processo de identificação, observamos que, além da interiorização, a totalidade concreta das relações sociais também rege a re-posição da identidade impregnada destas tipificações. Nos casos de submissão a estes valores, por mais que a pessoa em situação de rua busque a alternação de sua identidade, estes valores pejorativos permeiam suas relações sociais e impedem-na de fazê-lo. Pode-se considerar, nestas circunstâncias, que, em casos de "estigmatizações", o indivíduo “... não tem virtualmente defesa subjetiva contra a identidade que lhe é atribuída", ou seja, "é prisioneiro da realidade objetiva de sua sociedade..." (BERGER e LUCKMANN, 1985, p. 217-218).

Assim, a re-posiç̃o ininterrupta da identidade objetivamente atribuída pode cercear sua liberdade individual, fazendo com que a pessoa caminhe em uma "réplica de si mesmo". Embora seja de sua vontade, a possibilidade do novo, de novas personagens, faz com que adentre em um círculo vicioso da "crise do ator-sem-personagem". Esta condição pode ser entendida baseando-se no que Ciampa (1990) denomina como sendo uma "mesmice de si imposta". O indivíduo é levado a reproduzir uma identidade involuntariamente por força dos processos sociais que o tem como "tipo". Esta negação da sua humanidade é veiculada a partir de interesses que fogem do seu controle. Nas palavras de Ciampa (1990):

De qualquer forma, é o trabalho de re-posição que sustenta a mesmice. Outros são levados a essa situação, involuntariamente, quando o seu desenvolvimento é de alguma forma prejudicado, barrado, impedido; na nossa sociedade, encontramos milhões de exemplos de pessoas submetidas a condições sócio-econômicas desumanas; às vezes, mesmo com condições sócio-econômicas favoráveis, milhares, talvez milhões, de pessoas são impedidas de se transformar, são forçadas a se reproduzir como réplicas de si, involuntariamente, a fim de preservar interesses estabelecidos, situações convenientes, interesses e conveniências que são, se radicalmente analisados, interesses e conveniências do capital (e não do ser humano, que assim permanece um ator preso à mesmice imposta) (p. 165).

Por fim, entorpecida nestas condições, a pessoa pode vivenciar "a mutilação de sua vida de diferentes formas", o sofrimento ético-político, a "negação imposta socialmente", enfim, a "dor que surge da situação social de ser tratado como inferior, subalterno, sem valor, apêndice inútil da sociedade" (SAWAIA, 1999, p. 104). Sawaia aponta o suicídio como uma possível expiação deste sofrimento. Trilhando idéias similares, Ciampa (1990) 
pondera que na mesmice de si imposta, na crise do ator-sem-personagem, “... o ator caminha para a morte, simbólica ou biológica. A loucura, neste sentido, é o esforço de criação de um novo universo louco porque singular, não compartilhado - conseqüentemente fuga de uma realidade: a realidade quotidiana" (p.157).

Talvez por isso, vemos algumas pessoas em situação de rua caminhando a esmo, de cabeça baixa e expressão desconsolada. É possível surgir desta condição a loucura como forma de fugir da realidade que nega-as em sua humanidade: "Afinal de contas, se raramente você é o destinatário de qualquer atenção positiva ou é completamente ignorado, criar e se isolar numa realidade privada que lhe dá percepções privilegiadas e status especial pode ser mais adaptativo do que parece à primeira vista" (SNOW e ANDERSON, 1998, p. 340). Ou mesmo recorrer ao suicídio e "ter vontade só de morrer" como relata o ex-morador de rua Carlos Donizete Duarte (TRECHEIRO, Ano XII, $\mathrm{n}^{\circ}$ 105, $\mathrm{p}$ 02 ), que se jogou na frente de um carro e, felizmente, foi confundido como cego e auxiliado a atravessar a rua.

Porém, como vimos, as tipificações sobre as pessoas em situação de rua possuem em si o seu contrário, o germe de sua superação: se podem negar a humanidade destas pessoas, podem também serem elaboradas de forma a possibilitar a expressão e afirmação de suas humanidades. Carregando em si sua própria negação, tais tipificações dão margem à "vozes dissonantes", à causa revolucionária de pessoas em situação de rua que elaboram tais referências negativas por meio da luta pelos seus direitos. Fazem germinar daí a constituição de suas autonomias como sujeitos históricos e autores de suas transformações sociais.

Desta forma, essas tipificações podem gerar a submissão e a reprodução da dominação: o ato de alienar-se do mundo que as torna objeto e, por meio da loucura, criar um mundo imaginário no qual elas podem ser sujeitos humanos; ou mesmo abdicar da luta, e, já que não podem ser autoras de suas vidas, que o sejam de suas mortes, com o suicídio. Porém, podem utilizar-se de tais tipificações como ensejo para atitudes de resistên cia e transformação social, negando a negação de suas humanidades nelas contida: indignar-se e lutar, fazendo germinar a vida da possibilidade da morte. Trata-se, na concepção de Escorel (2000) de pessoas que "vivem de teimosas", pois, mesmo vendo reduzido seus campos de possibilidades, rom pem estas restrições e criam novas oportunidades de constituir-se enquanto protagonistas ativos da constituição daquela mesma sociedade que nega
Psicologia \& Sociedade; 16 (2): 47-58; maio/ago.2004

a elas essas mesmas oportunidades.

\section{REFLEXÕES FINAIS}

No ponto de intersecção entre o conceito de identidade como metamorfose humana e de representações sociais, discutimos o mecanismo da tipificação como forma de cristalizar e sustentar relações de dominação e exploração no âmbito da identidade pessoal. No que se refere às pessoas em situação de rua, estas tipificações surgem sob a feição de apreendê-las como vagabundas, sujas, loucas, perigosas e coitadas - que suscitam atitudes que vão da total indiferença à hostil violência física. Tal conhecimento compartilhado materializa-se nas relações sociais destes indivíduos servindo como material simbólico utilizado para a constituição de suas identidades.

Com efeito, as maneiras com as quais as pessoas em situação de rua elaboram estes conteúdos foram analisados a partir da submissão, materializando a loucura e o suicídio, ou da práxis transformadora, constituindo movimentos sociais na luta por seus direitos e reivindicações históricas.

Tal como as pessoas em situação de rua, nós, pesquisadores e cientistas sociais, também podemos elaborar de formas distintas as tipificações comumente fomentadas em nossa sociedade. Podemos, por um lado, em nossas pesquisas, nos resignarmos a tais conteúdos e reproduzir relações de dominação alinhadas aos ideais neoliberais: considerando que a culpa pela situação de rua é somente das pessoas que vivenciam tal condição e que cabe a nós, "donos do saber", orientá-las, submetendo-as aos nossos valores. Em contrapartida, temos a possibilidade de negar estas tipificações, atribuindo a essas pessoas a condição histórica de lutar junto a nós para a transformação desta realidade social. Neste último caso, faremos realmente uma Psicologia Social "enquanto práxis" (LANE e BOCK, 2003), como disciplina a serviço das classes populares para construir, junto com elas, uma sociedade mais justa. Na primeira possibilidade, não obstante, não faremos senão reproduzir uma Psicologia "elitista", ou seja, como disciplina subserviente ao ideal neoliberal e “... instrumento de controle social das classes subalternas utilizado pelas classes dominantes para perpetuar o sistema vigente de dominação e exploração" (ANDERY, 1984, p. 33). 
Mattos, R.M.; Ferreira, R.F. "Quem vocês pensam que (elas) são? Representações sobre as pessoas em situação de rua"

NOTA

*O presente artigo está atrelado ao trabalho de Iniciação Científica realizado por Ricardo Mendes Mattos, intitulado "Processo de constituição da identidade do indivíduo em situação de rua: da rualização a sedentarização", que possui a colaboração da Universidade São Marcos e o patrocínio da Fundação de Amparo à Pesquisa do Estado de São Paulo (FAPESP).

\section{REFERÊNCIAS}

ANDERY, A. A. Trabalhos em comunidade: seu significado para a produção de novos conhecimentos científicos. Psicologia, Ciência e Profissão, São Paulo, vol. 1, n. 4, p. 30-33, 1984.

BAPTISTA, M. T. Identidade profissional: questões atuais. In: DUNKER, C. I. L.; PASSOS, M. C. (Orgs.) Uma psicologia que se interroga: ensaios. São Paulo: Edicon, 2002. p. 145-154.

BARBOSA, J.; PAULINO, S. Identidade perdida: memórias de um morador de rua. São Paulo: Legnar, 2003.

BERGER, P. \& LUCKMANN, T. A construção social da realidade. Petrópolis: Vozes, 1985.

BUARQUE, C. Olhar a (da) rua. In: BURSZTYN, M. (Org.). No meio da rua: nômades excluídos e viradores. Rio de Janeiro: Garamond, 2000. p. 710

BURSZTYN, M. Da pobreza à miséria, da miséria à exclusão: o caso das populações de rua In: BURSZTYN, M. (Org.). No meio da rua: nômades excluídos e viradores. Rio de Janeiro: Garamond, 2000. p. 27-54.

CIAMPA, A.C. A identidade social e suas relações com a ideologia. 1977. 147 f. Dissertação (Mestrado em Psicologia Social). Pontifícia Universidade Católica de São Paulo, São Paulo.

CIAMPA, A. C. A estória do Severino e a história da Severina: um ensaio de Psicologia Social. 2. ed. São Paulo: Brasiliense, 1990.

COSTA, A. P. \& MAGALHÃES, P. S. Com a palavra, a imagem: moradores em situação de rua e o movimento dos sem-terra. (Trabalho de Conclusão de Curso em Comunicação Social) São Paulo: Universidade Anhembi Morumbi, 2002.
DI FLORA, M. C. Mendigos: porque surgem, por onde circulam, como são tratados? Petrópolis: Vozes, 1987.

DOMINGUES JR., P. L. População de rua, cooperativa e construção de uma "cidadania" (um estudo de caso sobre a COOPAMARE - Cooperativa dos Catadores Autônomos de Papel, Aparas e Materiais Reaproveitáveis Ltda.). 158 f. 1998. Dissertação (Mestrado em Administração) - Pontifícia Universidade Católica de São Paulo, São Paulo.

ESCOREL, S. Vivendo de teimosos: moradores de rua da cidade do Rio de Janeiro In: BURSZTYN, M. (Org.) No meio da rua: nômades excluídos e viradores. Rio de Janeiro: Garamond, 2000, p. 139171.

ENRIQUEZ, E. Perda do trabalho, perda da identidade. In: NABUCO. M. R. \& CARVALHO NETO, A. (Orgs.). Relações de trabalho contemporâneas. Belo Horizonte: IRT (Instituto de Relações do Trabalho) da PUC/MG, 1999. p. 69-83.

FURTADO, O. \& GOLZÁLEZ REY, F. L. (Orgs.). Por uma epistemologia da subjetividade: um debate entre a teoria sócio histórica e a teoria das representações sociais. São Paulo: Casa do Psicólogo, 2002.

GUARESCHI, P. A. A ideologia: um terreno minado. Psicologia e Sociedade, São Paulo, vol. 8, n. 2, p. 82-94, 1996.

GUARESCHI, P. A. Pressupostos psicossociais da exclusão: competitividade e culpabilização. In: SAWAIA, B. (Org.). As artimanhas da exclusão: análise psicossocial e ética da desigualdade social. Petrópolis: Vozes, 1999. p.141-156.

GUARESCHI, P. A. Relações comunitárias, relações de dominação. In CAMPOS, R. H. F. (Org.). Psicologia social comunitária: da solidariedade à autonomia. Petrópolis: Vozes, 2000. p. 81-100.

GUARESCHI, P. A. Ideologia. In: JACQUES, M. G. C. et al. (Orgs.). Psicologia social contemporânea. Petrópolis: Vozes, 2002. p. 89-103.

HAYASHIDA, E. A economia solidária como alternativa à situação de rua. 2003. 35 f. Iniciação Científica (Serviço Social), Pontifícia Universidade Católica de São Paulo, São Paulo.

JACQUES, M. G. C. Identidade e trabalho: uma 
articulação indispensável. In: TAMOYO, A.; BORGES-ANDRADE, J. E. \& CODO, W. (Orgs.) Trabalho, organizações e cultura. São Paulo: Cooperativa de Autores Associados, s.d. p. 41-47.

JODELET, D. As representações sociais. Rio de Janeiro: Ed. UERJ, 2001.

JORNAL "O TRECHEIRO: notícias do povo da rua". Ano X, no 98, junho/2002.

JORNAL "O TRECHEIRO: notícias do povo da rua". Ano XII no 105, fevereiro/2003.

JORNAL "O TRECHEIRO: notícias do povo da rua". Ano XII no 108, maio/2003.

LANE, S. T. M. \& BOCK, A. M. B. ABRAPSO - uma história da Psicologia Social enquanto práxis. In JACO-VILELA, A. M.; ROCHA, M. L. \& MANCEBO, D. (Orgs.) Psicologia Social: relatos na América Latina. São Paulo: Casa do Psicólogo, 2003, p. 145155.

MAGNI, C.T. Nomadismo urbano: uma etnografia sobre os moradores de rua em Porto Alegre. 1994. 198 f. Dissertação (Mestrado em Antropologia Social). Universidade Federal do Rio Grande do Sul, Porto Alegre.

MATTOS, R. M. Processo de constituição da identidade do indivíduo em situação de rua: da rualização a sedentarização. 2003. 186 f. (Iniciação Científica). Universidade São Marcos; FAPESP São Paulo.

MATTOS, R. M.; CASTANHO, M. I. S. \& FERREIRA R. F. Contribuição de Vygotsky ao conceito de identidade: uma leitura da autobiografia de Esmeralda. Estudos e Pesquisas em Psicologia, ano 3, n. 1, p. 119-138, 2003.

MATTOS, R.M.; TUCCI, Cléver e convidados. A situação de rua por ela mesma: relatos de sobreviventes. Semana de Psicologia da Universidade São Marcos, São Paulo, 2003. mimeo.

MOSCOVICI, S. A representação social da psicanálise. Rio de Janeiro: Zahar, 1978.

MOSCOVICI, S. Representações sociais. Investigações em psicologia social. Petrópolis: Vozes, 2003.

NASCIMENTO, E. P. Juventude: novo alvo da exclusão social. In: BURSZTYN, M. (Org.). No meio
Psicologia \& Sociedade; 16 (2): 47-58; maio/ago.2004 da rua: nômades excluídos e viradores. Rio de Janeiro: Garamond, 2000. p. 121-138.

NASSER, A.C. A. Sair para o mundo: trabalho, família e lazer: relação e representação na vida dos excluídos. 1996. 250 f. Tese (Doutorado em Sociologia) Faculdade de Filosofia, Letras e Ciências Humanas da Universidade de São Paulo. São Paulo.

OLIVEIRA, F.O. \& WERBA, G. C. Representações Sociais. In: JACQUES, M. G. C. et al. (Orgs.). PSicologia social contemporânea. Petrópolis: Vozes, 2002. p. $104-117$

ORTIZ, E.C. Esmeralda, por que não dancei. São Paulo: SENAC, 2001.

REVISTA BOCA DE RUA. Ano I, nº 0, dez./2000

REVISTA BOCA DE RUA. Ano I, nº 1, abril 2001.

REVISTA BOCA DE RUA. Ano I, nº 2, julho 2001.

REVISTA BOCA DE RUA. Ano I, n 3 , out/2001.

SAWAIA, B. O sofrimento ético-político como categoria de análise da dialética exclusão/inclusão. In: SAWAIA, B. (Org.). As artimanhas da exclusão: análise psicossocial e ética da desigualdade social. Petrópolis: Vozes, 1999. p.97-118.

SHIMABUKURO, P. A cooperação como alternativa à situação de rua: análise da experiência do MST. 2003. 37 f. Iniciação Científica (Serviço Social), Pontifícia Universidade Católica de São Paulo, São Paulo, 2003.

SNOW, D. \& ANDERSON, L. Desafortunados: um estudo sobre o povo da rua. Petrópolis: Vozes, 1998.

SPOSATI, A. Comentário sobre as formas de atuação com a população de rua. In: ROSA, C. M. M. (Org.). População de rua: Brasil-Canadá. São Paulo: Hucitec, 1995. p. 85-90.

STOFFELS, M. G. Os mendigos na cidade de São Paulo. Rio de Janeiro: Paz e Terra, 1977.

TOSTA, T. L. D. Memória das ruas, memórias da exclusão. In: BURSZTYN, M. (Org.). No meio da rua: nômades excluídos e viradores. Rio de Janeiro: Garamond, 2000. p. 201-229.

VIEIRA, M. A. C.; BEZERRA, E. M. R.; ROSA, C 
Mattos, R.M.; Ferreira, R.F. "Quem vocês pensam que (elas) são? Representações sobre as pessoas em situação de rua" M. M. População de Rua: quem é, como vive, como é vista. São Paulo: Hucitec, 1992.

ZALUAR, A. Comentários dos assessores sobre o perfil da população de rua. In: ROSA, C. M. M. (Org.). População de rua: Brasil-Canadá. São Paulo: Hucitec, 1995. p. 53-61.

Ricardo Mendes Mattos é graduando do Curso de Psicologia da Universidade São Marcos; colaborador do Fórum dos Estudantes Universitários vinculado ao CEPRUA (Centro de Estudos e Pesquisa sobre a População de Rua da Cidade de São Paulo) do Projeto Oficina Boracéia (Prefeitura de São Paulo). O endereço eletrônico do autor

$$
\text { é: ricardomendesmattos@ig.com.br }
$$

Ricardo Franklin Ferreira é Doutor em Psicologia Escolar e do Desenvolvimento Humano; coordenador e docente do Programa de Pós-Graduação em Psicologia da Universidade São Marcos. Linha de Pesquisa: Identidade - Formação e Transformação. $O$ endereço eletrônico do autor é: ricardo_franklin@uol.com.br

Ricardo Mendes Mattos e Ricardo Franklin Ferreira

Quem vocês pensam que (elas) são?

Representações sobre as pessoas em

situação de rua.

Recebido: 1/3/2004

$1^{\text {a }}$ revisão: $20 / 5 / 2004$

Aceite final: 28/6/2004 